\title{
La dermatología en la era genómica
}

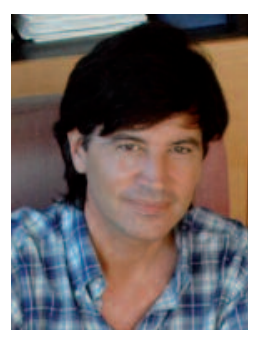

Carlos López-Otín Catedrático de Bioquímica y Biología Molecular. Universidad de Oviedo (Asturias).
Hace apenas seis décadas, un grupo de científicos, con diversa formación e intereses pero homogéneos en talento y en desencanto social, intuyeron que las claves esenciales de la vida y de las enfermedades podían llegar a explicarse a través del estudio de unas complejas y a la vez elegantes macromoléculas: los ácidos nucleicos y las proteínas. El descubrimiento en la primavera de 1953, por James Watson y Francis Crick, de la estructura en doble hélice del ADN constituyó el hito fundamental sobre el que se cimentó el progreso de la biología molecular, una ciencia joven que en poco tiempo ha cambiado la manera de entender nuestra vida y nuestro lugar en el mundo, y que tal vez en el futuro llegue a transformar también nuestra forma de vivir. Pocos años después, y como herencia científica directa de estos nuevos conceptos moleculares, se desarrollaron tecnologías mediante las cuales el ADN se pudo aislar, fragmentar y multiplicar de forma ilimitada. Además, se establecieron procedimientos para combinar los $\mathrm{ADN}$ de distintos organismos, y con ellos producir proteínas recombinantes con las características deseadas, que ya se utilizan en la actualidad para tratar numerosas enfermedades, incluyendo muchas de las que tienen un origen dermatológico.

La biología molecular, a través del Proyecto Genoma Humano, también nos ha aproximado al deseo de des- velar nuestros secretos moleculares más íntimos, incluso aquellos que, como dijo Fiódor Dostoievski, «no nos contamos ni a nosotros mismos». Así, hoy conocemos el orden preciso de los 3000 millones de nucleótidos que configuran nuestro material genético, y la forma en la que estas unidades químicas se organizan para construir los aproximadamente 25000 genes que determinan nuestras características como especie y que nos distinguen de los demás seres vivos con los que compartimos este astro azul sin luz propia que a todos nos acoge. De la misma manera, y apoyados en las nuevas técnicas de investigación biológica, hemos dirigido la atención hacia los genomas de otros organismos para compararlos con el nuestro y, así, extraer importantes lecciones acerca de las funciones que se han ido adquiriendo, modificando o incluso perdiendo, a medida que nuestra especie fue evolucionando. Paralelamente, a través de la comparación de distintos genomas humanos, hemos comenzado a definir las bases moleculares de la diversidad humana, escritas en el sutil lenguaje de los polimorfismos genéticos que configuran nuestras aptitudes, definen nuestras capacidades y determinan nuestra susceptibilidad individual a numerosas enfermedades. También hemos aprendido que el genoma se moldea con el epigenoma, esa forma de diálogo molecular entre ambiente y genoma, que, a través de cambios en la meti- 
lación del $\mathrm{ADN}$ o en las histonas que lo empaquetan, dispone sobre nuestro mensaje genético esos simbólicos acentos, puntos y comas, que finalmente determinan lo que somos y lo que parecemos. Por último, a través de grandes proyectos internacionales como el de los genomas del cáncer, hemos inaugurado una nueva era que pretende descifrar los genomas individuales de cada paciente, como estrategia definitiva para intentar desvelar las causas subyacentes al desarrollo de las patologías humanas. Sin duda, estas nuevas ideas encontrarán su máxima repercusión en el campo de la medicina molecular, esa disciplina individualizada, predictiva y regenerativa que pretende anticiparse al futuro desarrollo de las enfermedades de un individuo, a través del estudio de marcadores moleculares inscritos en el genoma, el epigenoma, el metagenoma, el varioma, el proteoma, el metaboloma, el degradoma o en cualquiera de los numerosos «omas» que configuran el lenguaje «ómico» de la ciencia actual. De este conocimiento, surgirán nuevos medicamentos con nombres que hoy todavía nos parecen extrañamente distintos y distantes. Así, los pacientes tendrán a su disposición una gran variedad de nuevos elixires biomédicos, incluyendo células reprogramadas, siguiendo la brillante estela marcada por Shinya Yamanaka. Y junto a células generadas «a la Yamanaka», encontraremos virus modificados genéticamente, ARN interferentes, oligonucleótidos antisentido, anticuerpos humanizados y todo tipo de proteínas recombinantes surgidas de la imaginación de los científicos y no de millones de años de evolución biológica.

La dermatología no ha permanecido ajena a este avance imparable y vertiginoso de la biología molecular para el que, lamentablemente, muchas facultades de medicina no han formado adecuadamente a los que deben ser sus principales intérpretes y protagonistas. Pese a ello, el progreso es luminoso y, por ejemplo, los denominados tratamientos biológicos ya permiten abordar en la actualidad problemas dermatológicos que antaño se tenían por imposibles, demostrando que la ciencia obli- ga a que «el concepto de imposible retroceda velozmente». En paralelo, y de manera que solo cabe definir como espectacular, en los últimos dos años se han descifrado los genomas tumorales de centenares de pacientes con melanoma. Las primeras imágenes del paisaje genético de este tipo de tumor tan agresivo muestran la apabullante complejidad que supone el hallazgo de varios miles de mutaciones en cada uno de los genomas estudiados, demostrando la existencia de una auténtica tormenta mutacional que se abate sobre las células de estos enfermos. Por fortuna, en medio de este naufragio genómico, hay terreno para la esperanza terapéutica, al demostrarse la existencia de varias mutaciones recurrentes, de forma que, en algunos casos y en un alarde de precisión genética, se han encontrado exactamente las mismas mutaciones en pacientes distintos, un hecho extraordinario si recordamos que nuestro genoma posee tres mil millones de componentes y cualquiera de ellos es susceptible de ser dañado. Estos resultados han abierto una nueva vía hacia la identificación de los genes recurrentemente mutados a los que los tumores se vuelven adictos, los cuales se han convertido así en dianas preferentes de intervención terapéutica. Al hilo de estos hallazgos, y en apenas unos meses, palabras todavía crípticas para algunos como vemurafenib, vismodegib o ipilimumab se han incorporado con pleno derecho al lenguaje de la dermatología, un lenguaje que utiliza sin pudor palabras terminadas en «ib» $y$ «ab», para definir esos nuevos inhibido-

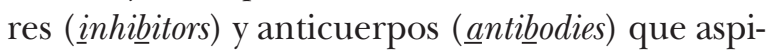
ran a regalar tiempo y vida a vuestros pacientes.

Nuestro propio laboratorio de la Universidad de Oviedo, casi sin pretenderlo, «por azar o por necesidad», también se ha aproximado al estudio molecular de la piel que habitamos, ese órgano que nos fascina por su tamaño y visibilidad, y que a la vez nos conmueve por su trascendencia funcional y vital. Así, analizando primero genes individuales y después genomas completos, nos hemos acercado a la abrumadora complejidad del cáncer, incluyendo la de los tumores de la piel, 
con la intención de encontrar respuestas frente a un mal que convierte a nuestras células en entidades egoístas, inmortales y viajeras que intentan quebrar la exquisita armonía con la que se desarrolla la aventura bioquímica de la vida. En este sentido, y gracias al esfuerzo y al talento de mis estudiantes y colaboradores, hemos podido demostrar que alguno de los nuevos genes humanos descubiertos en nuestro laboratorio y codificantes de metaloproteasas desempeñan funciones relevantes en la progresión de los melanomas metastásicos, mientras que, sorprendentemente, otros genes de las mismas familias proteolíticas nos protegen frente a dichos tumores.

Además, impulsados por nuestras investigaciones sobre los genes del cáncer, hemos comenzado a navegar sin prisa pero sin pausa hacia la exploración de los mecanismos moleculares de un proceso central en muchas consultas de dermatología: el envejecimiento humano, ese fenómeno natural que a todos nos alcanza e iguala y que parece inexorable, pero que tal vez en el futuro deje de serlo en alguna medida. Un observador externo podría decir que nuestro trabajo en este campo se ha aproximado directamente a la dermatología, al profundizar en el estudio de las temidas arrugas de la piel, pero un análisis cuidadoso de nuestros artículos en este sentido revelaría de inmediato que en realidad las arrugas a las que nos enfrentamos son otras muy distintas y mucho menos superficiales en todos los sentidos. Así, la labor experimental de nuestro grupo ha permitido demostrar que, en los pacientes con graves síndromes de envejecimiento prematuro y también en todos nosotros durante el envejecimiento normal, se acumulan en la membrana nuclear formas aberrantes de una proteína denominada prelamina A, generando profundas anomalías (a modo de arrugas nucleares) en dicha membrana que conducen de manera inapelable al envejecimiento celular y tisular. Estos estudios molecula- res han sido la clave para el desarrollo en nuestro laboratorio de los primeros tratamientos eficaces para alguno de los más devastadores síndromes progeroides humanos, tratamientos que tal vez en un futuro puedan aplicarse al control parcial del envejecimiento normal, aunque ello no representa en la actualidad ninguna prioridad en nuestra cita diaria con la ciencia.

Finalmente, y mediante el análisis comparativo y funcional de genomas, hemos tratado de avanzar en el estudio de la evolución humana, este hecho que una vez pareció imposible, impensable y hasta intolerable, pero que desde Darwin ya no admite dudas. Este viaje de conocimiento genómico a través de las fronteras de nuestro pasado y del de nuestros parientes más próximos en el árbol de la vida nos ha ayudado a comprender que debajo de la piel todos somos africanos, pues este es el origen de la especie Homo sapiens sapiens. Por ello y porque somos «hombres que sabemos que sabemos», nunca deberíamos olvidar que, pese a nuestro brillante y hasta exuberante policromatismo externo, todos poseemos un ancestro común que nos vincula directamente, incluso a quienes no lo desean, con un continente injustamente olvidado y marginado.

Y así, durante las tres últimas décadas, dando vueltas alrededor del sol a bordo de un laboratorio asturiano, y navegando entre genes y genomas, hemos intentado averiguar a nuestra manera si «debajo de la piel vive la luna». No hemos tenido el talento del gran Neruda para encontrar una respuesta definitiva a esta profunda pregunta de improbable respuesta. Por ello, mientras nuestra epidermis se arruga hasta convertirnos «en nada y en olvido", nos tendremos que contentar con explorar otras cuestiones más sencillas acerca de la vida y las enfermedades, y seguir conversando con las gigantes y elegantes moléculas que habitan en el fascinante mundo minúsculo que late bajo nuestra propia piel. 